\title{
Laparoscopic Removal of an Intra Abdominal Needle: Case Report and Review of the Literature
}

\author{
Naftali Timna*, Schwarz Ivan and Konikoff Fred \\ Department of Gastroenterology, Meir Medical Center Tel Aviv University, Israel
}

Received: December 28, 2017; Published: January 08, 2018

*Corresponding author: Timna Naftali, Department of Gastroenterology, Meir Medical Center, Kefar Saba 44281, Israel, Tel: 972-9-7472580; Fax: 972-97472725; Email: naftali@post.tau.ac.il

\begin{abstract}
Abdominal foreign bodies may cause severe complications such as infections, injury of an organ and perforation: There are not enough data for clear recommendations as to how such foreign bodied should be treated, if at all. We describe here a case of a needle found and removed laparoscopically in the abdominal cavity of a young healthy male. Review of the literature disclosed many anecdotal reports of foreign bodies that caused various complications, but currently no evidence based policy can be recommended. The rational for treating abdominal foreign bodies is discussed.
\end{abstract}

Keywords: Foreign Body; Laparoscopy; Foreign body complications

\section{Introduction}

Abdominal foreign bodies may be found either incidentally or in the search for the cause of abdominal symptoms. The real prevalence of asymptomatic abdominal foreign bodies is not known. In a rare study, Ahn et al looked at abdominal plain X-rays and CT's of 871 patients referred to the emergency room for abdominal pain. They found foreign bodies in 8 (1\%) of the patients [1]. Most other reports about abdominal foreign bodies are anecdotal. There are no studies on the prevalence and natural history of foreign bodies in a cohort of an asymptomatic population. Thus the actual prevalence and natural history of the problem remains unknown. Numerous foreign objects have been found in the abdomen. Some are related to previous medical procedures, such as retained surgical instruments, migrating medical objects such as IUD [2,3], stents [4], catheters [5], pace makers [6,7] or surgical clips [8].

Other metallic objects include swallowed coins [9] or needles $[10,11]$ and gunshot bullets. Non metallic objects have also been described, most commonly forgotten surgical gausses, also known as gossipibomas [12,13]. Bones [14], pencils [15] and even a bottle cup [16] have been described. Symptoms of an abdominal foreign body vary with the nature and location of the object. Some, such as bullets or retained bomb particles, may stay in the body for many years without causing any symptoms. This can often be seen in people who were injured in battle. Sharp metal objects are of more concern as they may migrate to other organs and cause complications including perforations. A gossipiboma may be the cause of infection, foreign body reaction and even perforation. We describe a case of a needle which was found in the abdomen of a healthy young male and was probably swallowed 20 years earlier.

\section{Case Presentation}

A 32 years old healthy male presented to the gastroenterology clinic because of abdominal pain. The pain was sharp, of short duration, and was induced by certain movements or postures, like bending forward. He described the pain as "a needle prick". Plain abdominal X-ray indeed showed a needle, almost 4 centimeters long, in the upper abdomen slightly left to the midline. Gastroscopy was normal. Barium swallow showed that the needle was outside the intestinal tract, extending towards the third part of the duodenum. Endoscopic ultrasound confirmed the finding. CT showed a long thin metallic object, beneath the pancreas, close to the superior mesenteric artery, in the peritoneal fat outside the wall of the intestinal tract.

The patient could not recall how the needle got there, but his mother remembered that when he was 9 years old he had a toy that contained such needles and it was assumed that he may have swallowed a needle at that time. We assumed that the needle migrated slowly to the present location. The proximity of the needle to major blood vessels raised a concern that it might continue to migrate into a blood vessel and it was therefore decided to have it removed. Under general anesthesia a $10 \mathrm{~mm}$ optic fiber was inserted into the abdomen at an angle of $35^{\circ}$. Exploration with the fiber could not locate the foreign body and a plain abdominal film was 
taken. The needle was identified along the mesocolon which was then dissected. The area was marked by metal clips and another abdominal film was taken. The needle was identified under the third part of the duodenum laterally to the superior mesenteric artery, but almost touching it. The optic fiber was gradually progressed towards the needle which was exposed by careful dissection and removed.

\section{Discussion}

Abdominal foreign bodies usually come to clinical attention only if they cause a complication. The true incidence of asymptomatic abdominal foreign bodies is therefore unknown and may be higher than estimated. When an asymptomatic or minimally symptomatic abdominal foreign body is found, the question arises whether the risk of a future complication justifies intervention and removal of the object. Certain foreign objects, such as gossipibomas, result in a complication so frequently that they certainly justify intervention. Gossipibomas have been reported to become infected, migrate [13], behave like a pseudo tumor [12] and even cause perforations. Therefore the consensus is that they should be removed. Sharp metal objects are also likely to cause complications. Such objects have been reported to migrate, cause abdominal symptoms, infections [8] and also perforations [17].

Blunt metal objects, such as bullets or metal parts have been observed to stay in the body for long periods of time without causing any complications. This has been reported in people who were wounded in a blast or by a gun shot. However, even such relatively benign foreign objects may cause complications including lead toxicity [18]. Other metal objects described to cause complications are retained surgical instruments [19]. Even round blunt metal objects, such as coins have been reported to cause perforations [20]. In our case the patient had very mild symptoms: slight abdominal pain mainly induced by body movements. However, the object was a sharp metallic one which had most probably migrated during the years and was in very close proximity to a major blood vessel. We therefore decided that the risk of leaving the foreign body in place outweighs the risk of removing it. The needle was removed successfully by laparoscopy and one year after the operation the patient feels well, and is pain free.

\section{References}

1. Ahn SH, Mayo Smith WW, Murphy BL, Reinert SE, Cronan JJ (2002) acute nontraumatic abdominal pain in adult patients: abdominal radiography compared with CT evaluation. Radiology 225(1): 159-164.

2. Levsky JM, Herskovits M (2005) Incidental detection of a transmigrated intrauterine device. Emerg Radiol 11(5): 312-314.

3. Miranda L, Settembre A, Capasso P, Cuccurullo D, Pisaniello D, et al. (2003) Laparoscopic removal of an intraperitoneal translocated intrauterine contraceptive device. Eur J Contracept Reprod Health Care 8(2): 122-125.

4. Melita G, Curro G, Iapichino G, Princiotta S, Cucinotta E (2005) Duodenal perforation secondary to biliary stent dislocation: a case report and review of the literature. Chir Ital 57(3): 385-388.

5. Park CK, Wang KC, Seo JK, Cho BK (2000) Transoral protrusion of a peritoneal catheter: a case report and literature review. Childs Nerv Syst 16(3): 184-189.

6. Garcia-Bengochea J, Rubio J, Sierra J, Fernandez A (2003) Pacemaker migration into the pouch of Douglas. Tex Heart Inst J 30(1): 83.

7. Leonelli FM, Salley R, Szabo TS, Kuo CS (1997) the vanishing defibrillator syndrome: incidence, mechanism, and clinical relevance. Pacing Clin Electrophysiology 20(4): 960-965.

8. Grubb K, Gagandeep S, Chatzoulis G, Basa N, Palmer S, et al. (2005) Surgical clips: a nidus for foreign body reaction. Surg Laparosc Endosc Percutan Tech 15(6): 363-365.

9. Halverson JM, Butterman MK, Legier JF, Mann WJ, Hoefer RA (1994) Perforation of a Meckel's diverticulum caused by ingestion of a coin. South Med J 87(8): 823-824.

10. Harjai MM, Gill M, Singh Y, Sharma A (2000) Intra-abdominal needles: an enigma (a report of two cases). Int Surg 85(2): 130-132.

11. Omejc M (2002) Laparoscopic removal of an ingested pin migrating into the liver. Surg Endosc 16(3): 537.

12. Hemal AK, Singh I, Karan SC, Kumar M, Sharma MC, et al. (2000) retroperitoneal textiloma following laparoscopic-assisted nephroureterectomy for lower ureteric cancer, masquerading as a metastatic soft-tissue tumor. Aust N Z J Surg 70(6): 467-468.

13. Lauwers PR, Van Hee RH (2000) intraperitoneal gossypibomas: the need to count sponges. World J Surg 24(5): 521-527.

14. Byard RW, Gilbert JD (2001) Hepatic abscess formation and unexpected death: a delayed complication of occult intraabdominal foreign body. Am J Forensic Med Pathol 22(1): 88-91.

15. Kenigsberg K, Ashley R, DiCarmine F (1995) unusual injury caused by a pencil. J Pediatr Surg 30(6): 891-892.

16. O'Hanlan KA, Westphal LM (1995) First report of a vaginal foreign body perforating into the retroperitoneum. Am J Obstet Gynecol 173(3): 962964.

17. Gonzalez Ojeda A, Rodriguez Alcantar DA, Arenas Marquez H, Sanchez Perez Verdia E, Chavez Perez R, et al. (1999) Retained foreign bodies following intra-abdominal surgery. Hepatogastroenterology 46(26): 808-812.

18. Coon T, Miller M, Shirazi F, Sullivan J (2006) Lead toxicity in a 14-yearold female with retained bullet fragments. Pediatrics 117(1): 227-230.

19. Mendez LE, Medina C (1997) Late complication of laparoscopic salpingoophorectomy: retained foreign body presenting as an acute abdomen. JSLS 1(1): 79-81.

20. Halverson JM, Butterman MK, Legier JF, Mann WJ, Hoefer RA (1994) Perforation of a Meckel's diverticulum caused by ingestion of a coin. South Med J 87(8): 823-882

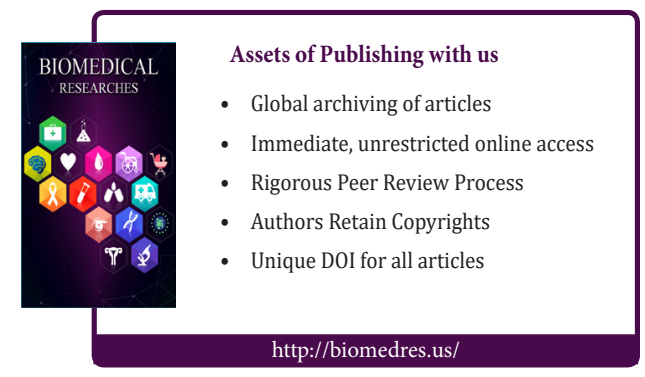

